\title{
Relation of angiographically defined coronary artery disease to plasma lipoprotein subfractions and apolipoproteins
}

\author{
N E MILLER, F HAMMETT, S SALTISSI, S RAO, H VAN ZELLER, J COLTART, B LEWIS
}

\begin{abstract}
The relation of coronary artery disease to plasma lipoproteins was examined in 104 men aged 35-65 years undergoing coronary angiography for suspected myocardial ischaemia. A score reflecting the number, degree, and length of stenoses in seven major coronary arteries was assigned to each angiogram. Lipid concentrations in lipoprotein subfractions were measured after preparative ultracentrifugation; plasma apolipoprotein concentrations were measured by electroimmunoassay.

Men with high coronary scores tended to have lower plasma high-density lipoprotein (HDL) cholesterol concentrations and higher low-density lipoprotein (density 1.019-1.063 $\mathrm{g} / \mathrm{ml}$ ) cholesterol concentrations than subjects of similar age with low coronary scores $(p \approx 0 \cdot 1)$. The strongest relation, however, was with the cholesterol concentration in the $\mathrm{HDL}_{2}$ subfraction (density 1.063$1.125 \mathrm{~g} / \mathrm{ml}$ ) of $\mathrm{HDL}$, which averaged $44 \%$ lower in the severely affected patients $(p<0.005)$. No associations were found between the coronary score and $\mathrm{HDL}_{3}$ cholesterol, the cholesterol content of lipoproteins of density $<1.019 \mathrm{~g} / \mathrm{ml}$, plasma triglyceride, or the concentrations of apolipoproteins $A I$, AII, and $E$.
\end{abstract}

The high coronary scores associated with low $\mathrm{HDL}_{2}$

St Thomas's Hospital Medical School, London SE1 7EH

N E MILLER, MD, MRCPATH, senior lecturer and honorary consultant, department of chemical pathology and metabolic disorders

F HAMMETT, BSC, medical laboratory scientific officer

$S$ SALTISSI, MB, MRCP, senior research fellow in cardiology and nuclear medicine (present address: North Tees General Hospital, Stockton)

$S$ RAO, BSC, PHD, lecturer, department of chemical pathology

H VAN ZELLER, BSC, research fellow

J COLTART, MD, MRCP, consultant physician

B LEWIS, FRCP, FRCPATH, professor of chemical pathology concentrations reflected an increase in the number of both partial and complete stenoses distributed throughout the coronary tree. In contrast the sizes of the lesions and the proportion producing complete occlusion were unrelated to $\mathbf{H D L}_{2}$.

\section{Introduction}

Epidemiological studies have established that the prevalence and incidence of clinical ischaemic heart disease in Western communities are correlated positively with the plasma lowdensity lipoprotein (LDL) concentration and negatively with the high-density lipoprotein (HDL) cholesterol concentration..$^{1-5}$ Angiographic studies have shown that the severity of coronary artery disease also increases with increasing LDL concentration and with decreasing $\mathrm{HDL}$ concentration. ${ }^{6-8}$ Both of these classes of plasma lipoproteins are heterogeneous. LDL, as originally defined, is composed of two major subfractions, $\mathrm{LDL}_{1}$ (or intermediate-density lipoprotein) and $\mathrm{LDL}_{2}$, the first subfraction having the lower density and the higher ratio of triglyceride to cholesterol. ${ }^{9} \mathrm{HDL}$ is also composed of two major subfractions, $\mathrm{HDL}_{2}$ and $\mathrm{HDL}_{3} ; \mathrm{HDL}_{2}$ is the minor subfraction but has the greater ratio of cholesterol to protein. ${ }^{\circ}$ Metabolic studies indicate that $\mathrm{LDL}_{2}$ is normally derived from the catabolism of $\mathrm{LDL}_{1}{ }^{10} ; \mathrm{HDL}_{2}$ may be produced by the fusion of $\mathrm{HDL}_{3}$ with the surface remnants of triglyceride-rich lipoproteins. ${ }^{11}$

There are no published data on the relation of angiographically defined coronary artery disease to LDL and HDL subclasses. Such information could be of value in two ways. Firstly, identifying correlations of greater strength than those already recognised might improve our ability to assess the risk of ischaemic heart disease in individual subjects. Secondly, and more important, it might help to clarify the nature of the link between lipoprotein metabolism and atherogenesis. We have therefore measured the plasma concentrations of lipoprotein subfractions in patients undergoing coronary angiography. We also examined the relation of coronary disease to several apolipoproteins. 


\section{Subjects and methods}

The subjects were 104 men aged 35-65 years admitted to St Thomas's Hospital for coronary angiography for suspected ischaemic heart disease. Consecutive patients were studied, with the exception that those taking lipid-lowering agents or with valvular disease or a history of diabetes mellitus or coronary artery surgery were excluded. Several other patients were omitted because the recovery of plasma cholesterol during lipoprotein fractionation was less than $95 \%$. Plasma cholesterol and triglyceride concentrations were in the ranges $4 \cdot 0-8.0 \mathrm{mmol} / \mathrm{l}(154-309 \mathrm{mg} / 100 \mathrm{ml})$ and $0 \cdot 8-3.5 \mathrm{mmol} / \mathrm{l}$ (71-310 $\mathrm{mg} / 100 \mathrm{ml})$, respectively.

\section{ANGIOGRAPHY}

Coronary angiography was performed after passage of a Judkins pigtail catheter via the right femoral artery. The overall severity of disease was evaluated by assigning to the angiogram a score reflecting the number, degree, and length of stenoses in seven major vessels (right, posterior descending, left main, left anterior descending, circumflex, and the two obtuse marginal arteries). Each stenosis identified was given one score for the degree of narrowing $(<24 \%, 1$; $25-49 \%, 2 ; 50-74 \%, 3 ; 75-99 \%, 4)$ and another for its length ( $<5 \mathrm{~mm}$, $1 ; 5-10 \mathrm{~mm}, 2 ;>10 \mathrm{~mm}, 3)$. When an artery was completely occluded a score of 5 or 6 was given, the score of 5 being assigned when there was visible blood flow distal to the obstruction via collaterals. The sum of scores for all stenoses was then termed the coronary score; values ranged from 0 to 48 .

\section{PLASMA LIPOPROTEINS}

Blood was collected after a 14-hour overnight fast into disodium EDTA $(2.7 \mathrm{mmol} / 1 ; 1 \mathrm{mg} / \mathrm{ml})$. A $5 \mathrm{ml}$ aliquot of plasma was adjusted to a density of $1.019 \mathrm{~g} / \mathrm{ml}$ with aqueous $\mathrm{NaCl}-\mathrm{NaBr}$, centrifuged at $105000 \mathrm{~g}$ for 20 hours at $14^{\circ} \mathrm{C}$, and the supernatant containing verylow-density lipoproteins (VLDL; density $<1.006 \mathrm{~g} / \mathrm{ml}$ ) and $\mathrm{LDL}_{1}$ (density $1.006-1.019 \mathrm{~g} / \mathrm{ml}$ ) isolated by tube slicing. ${ }^{12}$ The $\mathrm{LDL}_{2}$ (density $1.019-1.063 \mathrm{~g} / \mathrm{ml}$ ) in the infranatant was precipitated with heparin and $\mathrm{MnCl}_{2}$ (final concentrations $\left.205 \mathrm{U} / \mathrm{ml}, 92 \mathrm{mmol} / \mathrm{l}\right){ }^{13}$ The supernatant (containing HDL) was then adjusted to a density of $1.125 \mathrm{~g} / \mathrm{ml}$ with $\mathrm{NaBr}$, centrifuged at $105000 \mathrm{~g}$ for 40 hours, and the new supernatant (containing $\mathrm{HDL}_{2}$; density $1.063-1.125 \mathrm{~g} / \mathrm{ml}$ ) isolated by tube slicing. The cholesterol concentrations in whole plasma, HDL, $\mathrm{HDL}_{2}$, and lipoproteins of density $<1.019 \mathrm{~g} / \mathrm{ml}$ were measured directly by enzymatic procedures (BoehringerMannheim, Catalogue No 187 313); $\mathrm{HDL}_{3}$ cholesterol (density $1 \cdot 125-1 \cdot 21 \mathrm{~g} / \mathrm{ml}$ ) and $\mathrm{LDL}_{2}$ cholesterol were calculated by difference. Triglyceride in whole plasma and lipoproteins of density $<1.019 \mathrm{~g} /$ $\mathrm{ml}$ were measured enzymatically (Boehringer-Mannheim, Catalogue No 166 448). The ratio of cholesterol to triglyceride in lipoproteins of density $<1.019 \mathrm{~g} / \mathrm{ml}$ was used as an index of $\mathrm{LDL}_{1}$ concentration. ${ }^{9}$

The plasma concentrations of the major protein components of HDL, apolipoproteins AI and AII, were assayed by rocket immunoelectrophoresis against rabbit antiserum to purified human apolipoproteins ${ }^{14}$; apolipoprotein $\mathrm{E}$, a component of VLDL, $\mathrm{LDL}_{1}$, and HDL, was also measured. ${ }^{14}$ Standard curves were constructed using serial dilutions of plasma pools of known apolipoprotein content.

The angiographic and lipoprotein measurements were made by different investigators, neither of whom knew the results of the other.

\section{Results}

The relation of coronary disease to the different measurements was examined by dividing the subjects into three groups based on the coronary scores: group 1 were those in the bottom fifth of scores (range $0-10 ; n=21)$, group 2 those in the middle three-fifths $(n=63)$, and group 3 those in the top fifth (range $31-48 ; n=20$ ). There were no significant differences between these groups in the usage of adrenergic beta-blocking agents, which are known to influence plasma lipoproteins. ${ }^{15}$

Table I gives the ages, body weights, systolic blood pressures, and plasma lipoprotein lipid and apolipoprotein concentrations in the three groups. Analysis by $t$ test (two-tailed) showed that subjects with severe disease (group 3 ) had significantly lower concentrations of $\mathrm{HDL}_{2}$ cholesterol than subjects in group $2(p=0.01)$ and group 1 $(p=0.005)$. The only other significant difference was a lower $\mathrm{LDL}_{2}$
TABLE I-Ages, weights, blood pressures, plasma lipoprotein lipid concentrations, and apolipoprotein concentrations in three groups of patients with differing degrees of coronary artery disease. Figures are means $\pm S E M$

\begin{tabular}{|c|c|c|c|}
\hline & $\begin{array}{l}\text { Group 1 } \\
(n=21)\end{array}$ & $\begin{array}{l}\text { Group 2 } \\
(n=63)\end{array}$ & $\begin{array}{c}\text { Group } 3 \\
(n=20)\end{array}$ \\
\hline $\begin{array}{l}\text { Age (years) } \\
\text { Weight (kg) } \\
\text { Systolic blood pressure }(\mathrm{mm} \mathrm{Hg}) \\
\text { Plasma triglyceride }(\mathrm{mmol} / \mathrm{l}) \\
\text { Cholesterol of density }<1.019 \mathrm{~g} / \mathrm{ml}\end{array}$ & $\begin{array}{r}49 \cdot 90 \pm 2 \cdot 00 \\
77 \cdot 30 \pm 2 \cdot 50 \\
130 \cdot 00 \pm 4 \cdot 40 \\
1 \cdot 88 \pm 0 \cdot 16\end{array}$ & $\begin{array}{r}49 \cdot 60 \pm 1 \cdot 20 \\
78 \cdot 60 \pm 1 \cdot 30 \\
129 \cdot 00 \pm 2 \cdot 60 \\
2 \cdot 01 \pm 0 \cdot 10\end{array}$ & $\begin{array}{r}49 \cdot 90 \pm 1 \cdot 90 \\
78 \cdot 70 \pm 2 \cdot 90 \\
128 \cdot 00 \pm 4 \cdot 30 \\
1 \cdot 82 \pm 0 \cdot 20\end{array}$ \\
\hline $\begin{array}{l}\left(\mathrm{mmol}^{2}\right) \\
\mathrm{LDL}_{2} \mathrm{cholesterol}(\mathrm{mmol} / \mathrm{l}) \\
\mathrm{Total}^{\mathrm{H}} \mathrm{HDL} \text { cholesterol }(\mathrm{mmol} / \mathrm{l}) \\
\mathrm{HDL}_{2} \text { cholesterol (mmol/1) } \\
\text { HDL }_{3} \text { cholesterol (mmol/1) } \\
\text { Cholesterol :triglyceride in density }\end{array}$ & $\begin{array}{l}1 \cdot 01 \pm 0 \cdot 12 \\
3 \cdot 00 \pm 0 \cdot 24 \\
1 \cdot 29 \pm 0.08 \\
0 \cdot 27 \pm 0.03 \\
1 \cdot 02 \pm 0.09\end{array}$ & $\begin{array}{l}1 \cdot 18 \pm 0.08 \\
3 \cdot 50 \pm 0 \cdot 11 \\
1 \cdot 24 \pm 0.05 \\
0 \cdot 23 \pm 0.02 \\
1 \cdot 00 \pm 0.05\end{array}$ & $\begin{array}{l}1 \cdot 08 \pm 0 \cdot 13 \\
3 \cdot 45 \pm 0 \cdot 20 \\
1 \cdot 11 \pm 0 \cdot 07 \\
0 \cdot 15 \pm 0 \cdot 02 \\
0 \cdot 95 \pm 0 \cdot 10\end{array}$ \\
\hline $\begin{array}{l}<1.019 \mathrm{~g} / \mathrm{ml} \\
\text { Apolipoprotein AI } \\
\text { Apolipoprotein AII } \\
\text { Apolipoprotein E }\end{array}$ & $\begin{array}{c}1 \cdot 08 \pm 0 \cdot 09 \\
108 \cdot 00 \pm 19 \cdot 00 \\
38 \cdot 00 \pm 3 \cdot 30 \\
5 \cdot 20 \pm 0 \cdot 18\end{array}$ & $\begin{array}{r}1 \cdot 08 \pm 0 \cdot 06 \\
123 \cdot 00 \pm 4 \cdot 90 \\
39 \cdot 00 \pm 2 \cdot 20 \\
4 \cdot 90 \pm 0 \cdot 08\end{array}$ & $\begin{array}{r}1 \cdot 07 \pm 0 \cdot 14 \\
110 \cdot 00 \pm 9 \cdot 00 \\
41 \cdot 00 \pm 4 \cdot 30 \\
4 \cdot 90 \pm 0.13\end{array}$ \\
\hline
\end{tabular}

Student's $t$ test (two-tailed)-Group $1 v$ group 3: $\mathrm{HDL}_{2}$ cholesterol, $\mathrm{p}=0.005$; total HDL cholesterol, $\mathrm{p}=0.09 ; \mathrm{LDL}_{2}$ cholesterol, $\mathrm{p}=0.14$. Group 1 v group 2 : $\mathrm{LDL}_{2}$ cholesterol, $\mathrm{p}=0.04$. Group $2 v$ group 3: $\mathrm{HDL}_{2}$ cholesterol, $\mathrm{p}=0.01$. Other

Conversion: SI to traditional units-Triglyceride: $1 \mathrm{mmol} / 1 \approx 88.5 \mathrm{mg} / 100 \mathrm{ml}$. Cholesterol: $1 \mathrm{mmol} / 1 \approx 38.6 \mathrm{mg} / 100 \mathrm{ml}$.

cholesterol concentration in group 1 than in group $2(p=0.04)$. Patients in group 1 also tended to have higher total HDL cholesterol concentrations and lower $\mathrm{LDL}_{2}$ cholesterol concentrations than those in group 3 , but these associations were not as strong $(p \approx 0 \cdot 1)$.

Comparison of groups 1 and 3 by the non-parametric MannWhitney $U$ test gave similar results to those obtained with the $t$ test: $\mathrm{HDL}_{2}$ cholesterol, $\mathrm{p}<0.002$; total $\mathrm{HDL}$ cholesterol, $\mathrm{p} \approx 0.05$; $\mathrm{LDL}_{2}$ cholesterol, $\mathrm{p} \approx 0 \cdot 10$.

Of several lipoprotein combinations examined, the best discriminator between subjects with severe disease and those with minimal disease was the ratio of $\mathrm{HDL}_{2}$ cholesterol to $\mathrm{LDL}_{2}$ cholesterol (table II). In the pooled data the correlation coefficient between the $\mathrm{HDL}_{2}: \mathrm{LDL}_{2}$ ratio and coronary score was $-0.23(\mathrm{p}<0.02)$.

TABLE II-Lipoprotein cholesterol ratios in patients with differing degrees of coronary artery disease. Figures are means $\pm S E M$

\begin{tabular}{|c|c|c|c|}
\hline & $\underset{(n=21)}{\text { Group 1 }}$ & $\underset{(n=63)}{\text { Group } 2}$ & $\begin{array}{c}\text { Group } 3 \\
(n=20)\end{array}$ \\
\hline $\begin{array}{l}\text { HDL cholesterol:LDL } \\
\text { HDL cholesterol } \\
\text { HDL }_{2} \text { cholesterol:HDL, cholesterol:LDL } \\
\text { LDolesterol }_{2} \text { cholesterol }\end{array}$ & $\begin{array}{l}0.472 \pm 0.051 \\
0.348 \pm 0.072 \\
0.106 \pm 0.017\end{array}$ & $\begin{array}{l}0.401 \pm 0.035 \\
0.278 \pm 0.021 \\
0.078 \pm 0.007\end{array}$ & $\begin{array}{l}0.347 \pm 0.042 \\
0.170 \pm 0.021 \\
0.044 \pm 0.004\end{array}$ \\
\hline
\end{tabular}

Student's $t$ test (two-tailed)-Group $1 v$ group 3: HDL:LDL, $p=0.069$; Student's $t$ test (two-tailed)-Group 1
$\mathrm{HDL}_{2}: \mathrm{HDL}_{3}, \mathrm{p}=0.035 ; \mathrm{HDL}_{2}: \mathrm{LDL}_{2}, \mathrm{p}=\mathbf{0} .0024$.

The association between $\mathrm{HDL}_{2}$ and coronary disease was explored further by comparing patients in the top and bottom fifths of values for $\mathrm{HDL}_{2}$ cholesterol concentration with respect to the number, nature, and distribution of stenoses. Table III gives the results. Patients with low $\mathrm{HDL}_{2}$ concentrations had a much greater number of stenoses (by 2.4 -fold; $p<0.002$ ). The additional lesions were widely distributed, increasing the number of affected arteries per

TABLE III-Number, nature, and distribution of coronary artery stenoses in patients in top and bottom fifths of values for $H D L_{2}$ cholesterol concentration

\begin{tabular}{|c|c|c|c|}
\hline & $\begin{array}{l}\text { Bottom } \\
\text { fifth }\end{array}$ & $\begin{array}{l}\text { Top } \\
\text { fifth }\end{array}$ & $\mathbf{p}^{*}$ \\
\hline $\begin{array}{l}\text { Mean HDL } \mathrm{H}_{2} \text { cholesterol (mmol/l) } \\
\text { Mean coronary score } \\
\text { No of patients with disease } \\
\text { No of patients with a complete occlusiont } \\
\text { No of diseased arteries per patient (mean) } \downarrow \\
\text { Total No of stenoses per patient (mean) } \\
\text { Percentage of stenoses producing complete occlusion }\end{array}$ & $\begin{array}{c}(n=20) \\
0 \cdot 13 \\
28 \cdot 3 \\
20 \\
13 \\
4 \cdot 2 \\
5 \cdot 7 \\
14 \cdot 0\end{array}$ & $\begin{array}{c}(n=19) \\
0.38 \\
10 \cdot 8 \\
13 \\
5 \\
2.3 \\
2.4 \\
11.0\end{array}$ & $\begin{array}{l}<0.002 \\
<0.01 \\
<0.02 \\
<0.01 \\
<0.002 \\
\quad \text { NS }\end{array}$ \\
\hline $\begin{array}{l}\text { Partial stenoses (mean scores): } \\
\text { Length } \\
\text { Degree of narrowing }\end{array}$ & $\begin{array}{l}1.79 \\
2.91\end{array}$ & $\begin{array}{l}1.98 \\
2.32\end{array}$ & NS \\
\hline
\end{tabular}

*Probability values obtained with Mann-Whitney $U$ test and $\chi^{2}$ test. NS $=p>0 \cdot 10$. *Probability values obtained with Mann-Whitney $U$ test and $\chi^{2}$ test. $\mathrm{NS}=\mathrm{p}>0 \cdot 10$.
tOnly two patients had more than one occlusion; both had low $\mathrm{HDL}_{2}$ concentrations. tOnly two patients had more than

Conversion: SI to traditional units-Cholesterol: $1 \mathrm{mmol} / 1 \approx 38.6 \mathrm{mg} / 100 \mathrm{ml}$. 
patient $(p<0.01)$. Low concentrations were also associated with a greater prevalence of complete occlusions $(p<0.02)$. On the other hand, the relative numbers of complete and partial stenoses and the average size of the partial stenoses (length and degree of narrowing) appeared to be unrelated to $\mathrm{HDL}_{2}$ concentration.

\section{Discussion}

The major finding in this study was that the inverse relation between clinical ischaemic heart disease and plasma total HDL cholesterol, previously shown epidemiologically, ${ }^{1-5}$ reflects an association between the severity of coronary artery disease and the cholesterol concentration in the $\mathrm{HDL}_{2}$ subclass. Coronary disease was also directly related to the $\mathrm{LDL}_{2}$ cholesterol concentration, but this association was weaker than that with HDL.. These two relations were independent of each other, the $\mathrm{HDL}_{2}: \mathrm{LDL}_{2}$ ratio being a better predictor of disease than either measurement alone. No other statistically significant associations were found. In particular, the coronary score was unrelated to age, body weight, and plasma triglyceride concentration, variables with which the total HDL cholesterol concentration has been shown to correlate in epidemiological studies. ${ }^{3} 516$

Closer examination of the angiographic data showed that the high coronary scores associated with low HDL.2 concentrations reflected an increase in the number of stenoses. This was true for both partial and complete stenoses. The additional lesions were widely distributed, showing no preference for any particular vessel. On the other hand, the average sizes of the lesions and the proportion that had progressed to produce a complete occlusion appeared to be unrelated to $\mathrm{HDL}_{2}$ concentration. Thus low $\mathrm{HDL}_{2}$ concentrations may be associated with an increased susceptibility to atherosclerotic lesions but not with an acceleration of the later stages of atherogenesis or with a predisposition to secondary thrombosis. Clearly, necropsy studies will be needed to confirm or refute this. Although the severity of atherosclerosis in coronary arteries showed a negative correlation with HDL cholesterol in the necropsy study of Solberg et al, ${ }^{17}$ these workers did not distinguish between complicated and uncomplicated lesions or measure HDL subfractions.

Our conclusion that it is principally $\mathrm{HDL}_{2}$ cholesterol rather than $\mathrm{HDL}_{3}$ cholesterol to which coronary disease is related is consistent with other published observations. In a 10-year prospective study of men aged 20-66 years reported in 1966 the mean $\mathrm{HDL}_{2}$ concentration (measured by analytical ultracentrifugation) in 38 subjects who developed clinical ischaemic heart disease was $32 \%$ lower $(p<0.01)$ than that in 1961 controls; the case-control difference in $\mathrm{HDL}_{3}$ concentration was substantially less $(-8 \%) .^{18}$ Later Albers et al ${ }^{19}$ noted that patients with a history of myocardial infarction had significantly lower ratios of HDL cholesterol to apolipoprotein AI than did healthy controls, consistent with a lower $\mathrm{HDL}_{2}: \mathrm{HDL}_{3}$ ratio in the former group. It has long been recognised that the low total HDL concentrations associated with hypertriglyceridaemia, male sex, and obesity chiefly reflect low $\mathrm{HDL}_{2}$ concentrations. ${ }^{20}$

Our evidence for a positive association between coronary disease and $\mathrm{LDL}_{2}$ cholesterol is consistent with and extends reports that angiographically defined disease is correlated with total LDL cholesterol. ${ }^{6-8}$ The absence of any relation between coronary disease and the cholesterol content of lipoproteins with a density below $1.019 \mathrm{~g} / \mathrm{ml}$ suggests that there was no association with $\mathrm{LDL}_{1}$ concentration in our subjects. There is little doubt that the very high $\mathrm{LDL}_{1}$ concentrations of familial type III hyperlipoproteinaemia contribute to the premature onset of atherosclerosis in that condition. ${ }^{21}$ In the rest of the community, however, the $\mathrm{LDL}_{1}$ concentration may not be a significant determinant of atherogenesis, though a high concentration produced locally at the arterial endothelial surface has been the subject of a plausible aetiological hypothesis. ${ }^{22}$

Our failure to discover a relation between coronary disease and the plasma concentrations of the major HDL apolipoproteins AI and AII is consistent with evidence that any reduc- 3 tion of apolipoprotein AI concentration in coronary victims is $\stackrel{\mathbb{Q}}{\varrho}$ less than that of HDL cholesterol. ${ }^{19}$ Apolipoprotein AI also $c$ appears to be a weaker predictor of coronary events than HDL $\widehat{\widehat{\Omega}}$ cholesterol. ${ }^{23}$ Avogaro et al, ${ }^{24}$ however, concluded that the $\overline{\bar{F}}$ concentrations of apolipoproteins $\mathrm{AI}$ and $\mathrm{B}$ (the major protein component of LDL) were more powerful than the plasma HDL o cholesterol and total cholesterol concentrations in discriminating between patients with a myocardial infarction and healthy controls.

Clinically our data suggest that assessing clinical coronary risk in a person is likely to be more accurate if based on the $\mathrm{HDL}_{2}$ cholesterol and $\mathrm{LDL}_{2}$ cholesterol concentrations than if based on the total HDL and plasma or total LDL cholesterol $\bar{\nabla}$ values. Biochemically the association of coronary disease with low $\mathrm{HDL}_{2}$ concentrations may provide clues to the nature of of the relation between HDL metabolism and atherogenesis. $\mathrm{HDL}_{2}$ may be produced by the fusion of $\mathrm{HDL}_{3}$ with surface remnants liberated from triglyceride-rich lipoproteins during their catabolism by lipoprotein lipase. ${ }^{11}$ This phenomenon appears to underlie the positive correlation between tissue lipoprotein lipase activity and HDL cholesterol concentration. ${ }^{25}$ i Thus a high $\mathrm{HDL}_{2}$ concentration may reflect an efficient ? lipolytic process, perhaps reducing the intravascular residence time of certain atherogenic intermediates. Also noteworthy is that $\mathrm{HDL}_{2}$ contains a particle which is rich in apolipoprotein $\mathrm{E}$ and that this competes with $\mathrm{LDL}_{2}$ for receptor-mediated \pm uptake by peripheral cells. ${ }^{26}$ Though we found no association between the severity of disease and the plasma apolipoprotein $\mathrm{E}$ concentration, only a proportion of this apolipoprotein resides in HDL. ${ }^{27}$

We are indebted to Dr P Alaupovic, of the Laboratory of Lipid $\vec{\bullet}$ and Lipoprotein Studies, Oklahoma Medical Research Foundation, $\stackrel{\infty}{-}$ and to Dr J J Albers, of the University of Washington, Seattle, for standardising the plasma pools used for the electroimmunoassays of apolipoproteins AI, AII, and E. This work was supported by a grant from the research endowments committee of St Thomas's Hospital. Ms C Whiting provided skilled technical help.

\section{References}

${ }^{1}$ Castelli WP, Doyle JT, Gordon T, et al. HDL cholesterol and other lipids in coronary heart disease. The Cooperative Lipoprotein Phenotyping Study Circulation 1977;55:767-72.

${ }^{2}$ Miller NE, Førde OH, Thelle DS, Mjøs OD. The Tromsø Heart Study. High-density lipoprotein and coronary heart disease: a prospective case-control study. Lancet $1977 ; \mathrm{i}: 965-8$.

${ }^{3}$ Gordon T, Castelli WP, Hjortland MC, Kannel WB, Dawber TR. High density lipoprotein as a protective factor against coronary heart disease. Am F Med 1977;62:707-14.

${ }^{4}$ Goldbourt U, Medalie JH. High density lipoprotein cholesterol and incidence of coronary heart disease-the Israeli Ischaemic Heart Disease Study. Am $\mathcal{f}$ Epidemiol 1979;109:296-308.

${ }^{5}$ Hulley SB, Rosenman RH, Bawol RD, Brand RJ. Epidemiology as a guide to clinical decisions: the association between triglyceride and coronary heart disease. N Engl f Med 1980;302:1383-9.

${ }^{6}$ Pearson TA, Bulkley BH, Achuff SC, Kwiterovich PO, Gordis L. The association of low levels of HDL cholesterol and arteriographically defined coronary artery disease. Am F Epidemiol 1979;109:285-95. ${ }^{7}$ Jenkins PJ, Harper RW, Nestel PJ. Severity of coronary atherosclerosis
related to lipoprotein concentration. Br Med $\mathcal{f}$ 1978;ii:388-91.

8 Tan MH, Macintosh W, Weldon KL, Kapoor A, Chandler BM, Hindmarsh TJ. Serum high density lipoprotein cholesterol in patients with abnormal coronary arteries. Atherosclerosis $1980 ; 37: 187-8$.

${ }^{9}$ Nichols AV. Human serum lipoproteins and their interrelationships. Adv Biol Med Phys 1967;11:109-58.

10 Janus ED, Nicoll A, Wootton R, Turner PR, Magill PJ, Lewis B. Quantitative studies of very low density lipoprotein conversion to low density lipoprotein in normal controls and primary hyperlipidaemic states and the role of direct secretion of low density lipoprotein in heterozygous familial hypercholesterolaemia. Eur f Clin Invest 1980;10:149-59.

${ }^{11}$ Patsch JR, Gotto AM Jr, Olivecrona T, Eisenberg S. Formation of high density lipoprotein ${ }_{2}$-like particles during lipolysis of very low density lipoproteins in vitro. Proc Natl Acad Sci USA 1978;75:4519-23.

12 Havel RJ, Eder HA, Bragdon JH. The distribution and chemical composition of ultracentrifugally separated lipoproteins in human serum. f Clin Invest $1955 ; 34: 1345-53$. 
13 Albers JJ, Warnick GR, Wiebe D, et al. Multi-laboratory comparison of three heparin- $\mathrm{Mn}^{2+}$ precipitation procedures for estimating cholesterol in high-density lipoprotein. Clin Chem 1978;24:853-6.

${ }^{14}$ Alaupovic P, Curry MD, McConathy WJ. Quantitative determination of human plasma apolipoproteins by electroimmunoassays. In: Carlson LA, Paoletti R, Sirtori CR, Weber G, eds. International conference on atherosclerosis. New York: Raven Press, 1978:109-15.

15 Anonymous. Antihypertensive drugs, plasma lipids and coronary disease. Lancet 1980;ii:19-20.

16 Gotto AM Jr, Miller NE, Oliver MF, eds. High density lipoproteins and atherosclerosis. Amsterdam: Elsevier/North-Holland, 1978.

17 Solberg LA, Enger SC, Hjermann I, et al. Risk factors for coronary and cerebral atherosclerosis in the Oslo study. In: Gotto AM, Smith LC Allen B, eds. Atherosclerosis V. Berlin: Springer-Verlag, 1980:57-62.

${ }^{18}$ Gofman JW, Young W, Tandy R. Ischemic heart disease, atherosclerosis and longevity. Circulation $1966 ; 34: 679-97$.

${ }^{19}$ Albers JJ, Cheung MC, Hazzard WR. High-density lipoproteins in myocardial infarction survivors. Metabolism 1978;27:479-85.

20 Gofman JW, DeLalla O, Glazier F, et al. The serum lipoprotein transport system in health, metabolic disorders, atherosclerosis and coronary heart disease. Plasma $1954 ; 2: 413-84$.

${ }^{21}$ Fredrickson DS, Levy RI, Lees RS. Fat transport in lipoproteins-an integrated approach to mechanisms and disorders. $N$ Engl $\mathcal{F ~} \mathrm{Med}$ $1967 ; 276$ :34-44.
22 Zilversmit DB. Atherogenesis: a postprandial phenomenon. Circulation w $1979 ; 60: 473-85$

${ }^{23}$ Ishikawa T, Fidge N, Thelle DS, Førde OH, Miller NE. The Tromsø Heart Study: serum apolipoprotein AI concentration in relation to 2 future coronary heart disease. Eur f Clin Invest 1978;8:179-82.

${ }^{24}$ Avogaro P, Bittolo Bon G, Cazzolato G, Quinci GB. Are apolipoproteins $\widehat{\Omega}$ better discriminators than lipids for atherosclerosis? Lancet 1979; i: 901-3.

${ }^{25}$ Nikkila EA. Metabolic and endocrine control of plasma high density $\underset{\mathbb{D}}{\mathbb{D}}$ lipoprotein concentration. Relation to catabolism of triglyceride-rich o lipoproteins. In: Gotto $\mathrm{AM} \mathrm{Jr}$, Miller NE, Oliver $\mathrm{MF}$, eds. High $\varrho$ density lipoproteins and atherosclerosis. Amsterdam: Elsevier/North- Holland, 1978:177-92.

${ }^{26}$ Weisgraber $\mathrm{KH}$, Mahley RW. Subfractionation of human high density $\stackrel{\vec{P}}{\vec{S}}$ lipoproteins by heparin-Sepharose affinity chromatography. $\mathcal{f}$ Lipid Res $1980 ; 21: 316-25$.

${ }^{27}$ Suenram A, McConathy WJ, Alaupovic P. Evidence for the lipoprotein $\overline{\bar{C}}$ heterogeneity of human plasma high density lipoproteins isolated by $\vec{D}$ three different procedures. In: Lindgren FT, Nichols AV, Krauss RM, 凤 eds. High density lipoproteins. Champaign, Illinois: American Oil \& Chemists Society, 1979:36-41.

(Accepted 2 April 1981)

\title{
Hepatic vascular lesions associated with dacarbazine treatment
}

\author{
M A GREENSTONE, PAULINE M DOWD, D P MIKHAILIDIS, P J SCHEUER
}

\begin{abstract}
Dacarbazine is widely used in the treatment of melanoma. Transient abnormalities of liver function tests are well-recognised side effects of the drug, but acute liver failure due to vascular occlusion in patients receiving single-agent chemotherapy with dacarbazine has been noted only rarely. Two cases are reported in which hepatic vascular lesions developed during treatment with dacarbazine and were confirmed at necropsy.

Hepatic vascular occlusion due to treatment with dacarbazine may be less rare than was previously thought. Greater caution may be needed when dacarbazine is prescribed, particularly as an adjuvant agent in stage I and II disease.
\end{abstract}

\section{Introduction}

Dacarbazine (dimethyl-triazeno-imidazole-carboxamide) has been widely used in the treatment of stage III melanoma and in trials of adjuvant chemotherapy in patients with stage I and II disease with a poor prognosis. We report two cases in which hepatic vascular lesions occurred during dacarbazine treatment.

\footnotetext{
Departments of Oncology and Dermatology, Royal Marsden Hospital, London SW3
}

M A GREENSTONE, MB, MRCP, senior house officer (present address : department of medicine, St Mary's Hospital, London W2)

PAULINE M DOWD, BSC, MRCP, honorary registrar (present address department of dermatology, St Bartholomew's Hospital, London EC1)

D $\mathbf{P}$ MIKHAILIDIS, BSC, $\mathrm{MB}$, senior house officer (present address : department of chemical pathology, Royal Free Hospital, London NW3)

Department of Histopathology, Royal Free Hospital, London NW3 P J SCHEUER, MD, FRCPATH, professor of clinical histopathology

\section{Case reports}

CASE 1

A 53-year-old Caucasian man developed histologically proved lymph-node metastases five years after wide excision of primary melanoma. In April 1978 he began treatment with dacarbazine ( $250 \mathrm{mg} / \mathrm{m}^{2}$ daily for five days). He was also taking amitryptiline (Lentizol) $50 \mathrm{mg}$ at night and chlorpromazine as required as an antiemetic. Apart from transient fever on the fifth day, he tolerated treatment well. One month later he was readmitted for a second course of dacarbazine. He was well, and clinical examination, full blood count, urea and electrolyte concentrations, and liver function tests were all normal. His medication was as before. He remained well until the fourth day of treatment, when he developed acute abdominal pain and hepatic tenderness. He deteriorated with confusion, jaundice, and hypotension. Results of liver function tests became extremely abnormal (aspartate transaminase activity $1780 \mathrm{U} / 1$, alkaline phosphatase activity $148 \mathrm{IU} / 1$, total bilirubin $77 \mu \mathrm{mol} / \mathrm{l}$ $(4.5 \mathrm{mg} / 100 \mathrm{ml})$ ), and he developed prolonged prothrombin and partial thromboplastin times, hypoglycaemia, and a profound meta- $\mathfrak{N}$ bolic acidosis. A peripheral blood film showed only mild neutrophilia $D$ $\left(74 \%\right.$ of $\left.13.9 \times 10^{9} / 1\right)$, whereas a differential white cell count two 을. days earlier had shown eosinophilia of $17 \%$ of $7 \times 10^{9} / 1$. Blood cultures were repeatedly negative. Despite vigorous supportive treatment he died 72 hours later.

At necropsy the liver had a mottled red appearance and irregular $\sigma$ areas of necrosis were seen. The main hepatic and portal veins were 0 patent. On microscopy recent infarcts were associated with fresh $\frac{\bar{D}}{\bar{D}}$

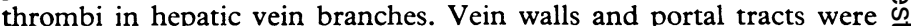
infiltrated with lymphocytes and eosinophils. There was a microscopic metastasis in one lung.

CASE 2

A 46-year-old Caucasian man was treated with dacarbazine $500 \mathrm{mg}$ 음 intravenously daily for five days for metastatic melanoma. He tolerated the first course of treatment well but on the third day of the second course developed clinical and laboratory manifestations of acute $\stackrel{\partial}{\supset}$ hepatic necrosis. There was no clinical evidence of drug hyper- 